\title{
The study of impact behaviour of two types of glass fibre reinforced polymer (GFRP) subjected to low velocity impact
}

\begin{abstract}
The aim of this work is to study the behaviour of two types of composite material when subjected to impacts at different energy levels under low velocity impact events. The composite material used in this study was Glass Fibre Reinforced Polymer (GFRP) which was C-type $/ 600 \mathrm{~g} / \mathrm{m} 2$ and E-type $/ 600 \mathrm{~g} / \mathrm{m} 2$. This material was fabricated to produce laminated plate specimens with a dimension of $100 \mathrm{~mm} 150 \mathrm{~mm}$. Each specimen had 10 layers of GFRP woven roving plies. The low velocity impact test was performed using an IM10 Drop Weight Impact Tester with a $10 \mathrm{~mm}$ hemispherical striker cap. The impact energy was set to $14,28,42$ and 56 joules with velocity ranging from $1.73 \mathrm{~m} / \mathrm{s}$ to $3.52 \mathrm{~m} / \mathrm{s}$. The relationships of impact energy with impact force, displacement and energy absorbed are presented. The comparison and behaviour between the two types of GFRP are discussed.
\end{abstract}

Keyword: Drop weight impact tester; Energy absorbed; Glass fibre reinforced polymer (GFRP); Low velocity impact (LVI) 